\title{
Effects of Indomethacin on Cerebral Vasodilator Responses to Arachidonic Acid and Hypercapnia in Newborn Pigs
}

\author{
CHARLES W. LEFFLER, ROBERT MIRRO,' MASAAKI SHIBATA, HELENA PARFENOVA, \\ WILLIAM M. ARMSTEAD, ${ }^{2}$ AND SAMUEL ZUCKERMAN
}

\begin{abstract}
Laboratory for Research in Neonatal Physiology, Brain Injury Research Center. Departments of Physiology and Biophysics, Pediatrics, and Obstetrics and Gynecology. University of Tennessee. Memphis, Tennessee 38163; and Critical Care-Pulmonary Medicine, St. Jude Children's Research Hospital, Memphis, Tennessee 38101.
\end{abstract}

\begin{abstract}
Responses of pial arterioles to topically applied arachidonic acid, conversion of exogenous arachidonic acid to prostanoids, and pial arteriolar dilation to hypercapnia were examined before and at progressive times after treatment with indomethacin $(5 \mathrm{mg} / \mathrm{kg}$ i.v. $)$ in chloralose-anesthetized newborn pigs with closed cranial windows. Before treatment with indomethacin, arachidonic acid and hypercapnia dilated pial arterioles and increased cortical periarachnoid cerebrospinal fluid concentrations of 6-keto-prostaglandin (PG) $F_{1 \alpha}$ and $\mathrm{PGE}_{2}$. One $\mathrm{h}$ after indomethacin treatment, the dilations and prostanoid synthesis were blocked. By $2 \mathrm{~h}$ after indomethacin treatment, hypercapnia produced significant dilation of pial arterioles, and dilation to both stimuli had returned to preindomethacin levels by $3 \mathrm{~h}$. Inhibition of conversion of exogenous arachidonic acid to prostanoids as monitored by increases in 6-keto-PGF ${ }_{1 \alpha}$ and $\mathrm{PGE}_{2}$ in cerebrospinal fluid under the window also was reversed by $3 \mathrm{~h}$ after treatment with indomethacin. Repeated indomethacin treatment again blocked dilations and conversion of arachidonic acid to prostanoids on the brain surface. The possibility of short duration of vascular effectiveness of indomethacin when it is administered systemically needs to be considered, both when it is used as a probe for understanding contributions of PGH synthase products to control of cerebral circulation and when it is used therapeutically in attempts to alter the newborn cerebral circulation. (Pediatr Res 33: 609-614, 1993)
\end{abstract}

\section{Abbreviations}

PG, prostaglandin

PGH synthase, prostaglandin $H$ synthase

CSF, cerebrospinal fluid

aCSF, artificial cerebrospinal fluid

LT, leukotriene

Indomethacin is widely used as a tool to study contributions of prostanoids to cerebral vascular control. Free indomethacin

Received November 6, 1992: accepted January 29. 1993.

Correspondence: Dr. Charles W. Leffler. University of Tennessee, Memphis, 894 Union Ave. (NA 427). Memphis. TN 38163.

R.M. was supported by a Clinical Investigatorship from the National Institutes of Health. H.P. is supported by a fellowship from the Tennessee Affiliate of the American Heart Association. The research was supported by National Institutes of Health Grants HL34059. HL42851. HL42875, and HL42939; and American Lebanese Syrian Associated Charities (ALSAC), and Cancer Center CORE Grant CA-21765.

Deceased, February 28, 1992.

${ }^{2}$ Present address: Department of Anesthesiology and Critical Care Medicine. Children's Hospital of Philadelphia, Philadelphia. PA 19104-4399. crosses the blood brain barrier (1), and a dose of $5 \mathrm{mg} / \mathrm{kg}$ i.v. inhibits conversion to prostanoids of arachidonic acid applied topically to the parietal cortex of piglets (2). In newborn pigs, such treatment with indomethacin also decreases cerebral blood flow (3) and blocks cerebral vasodilation in response to hypercapnia $(4,5)$, hypotension (6), and topically applied histamine (7). These stimuli increase cortical periarachnoid CSF concentrations of prostanoids, suggesting a functional association between the vasodilation and the prostanoid synthesis.

Indomethacin is a reversible inhibitor of PGH synthase (8). Therefore, when tissue levels of indomethacin fall sufficiently, inhibition will be lost concomitantly. It is generally assumed that the duration of action of indomethacin is long, but the plasma half-life is relatively short, and the CSF concentration is closely related to that of plasma (1). We have observed that repeated doses are often necessary to maintain inhibition of responses, and Lozon et al. (9) have reported that cerebral blood flow reactivity to hypercapnia in piglets returns by $2 \mathrm{~h}$ after treatment with $5 \mathrm{mg} / \mathrm{kg}$ of indomethacin.

The present experiments therefore examined, before and at progressive times after indomethacin, responses of pial arterioles to topically applied arachidonic acid and hypercapnia. The hypothesis addressed was that the return of responses to arachidonic acid and hypercapnia after indomethacin would coincide and both would again be lost after repeat indomethacin treatment.

\section{MATERIALS AND METHODS}

Newborn pigs ( 1 to $3 \mathrm{~d}$ old) were anesthetized with ketamine hydrochloride ( $33 \mathrm{mg} / \mathrm{kg}$ intramuscularly) and acepromazine (3.3 $\mathrm{mg} / \mathrm{kg}$ intramuscularly) and maintained on $\alpha$-chloralose (50 $\mathrm{mg} / \mathrm{kg}$ i.v. initially, plus $\left.5 \mathrm{mg} \cdot \mathrm{kg}^{-1} \cdot \mathrm{h}^{-1}\right)$. The animals were intubated and ventilated with air. Catheters were inserted in the femoral vein for maintenance of anesthesia and blood withdrawal and in the femoral artery to record blood pressure and draw samples for blood gas and $\mathrm{pH}$ analysis. Body temperature was maintained between 37 and $38^{\circ} \mathrm{C}$. The scalp was retracted, and a hole $2 \mathrm{~cm}$ in diameter was made in the skull over the parietal cortex. The dura was cut without touching the brain, and all cut edges were retracted over the bone so that the periarachnoid space was not exposed to damaged bone or damaged membranes. A stainless steel and glass cranial window was placed in the hole and cemented into place with dental acrylic. The space under the window was filled with aCSF $\left(150 \mathrm{mmol} / \mathrm{L} \mathrm{Na}^{+}, 3 \mathrm{mmol} / \mathrm{L}\right.$ $\mathrm{K}^{+}, 2.5 \mathrm{mmol} / \mathrm{L} \mathrm{Ca}^{2+}, 1.2 \mathrm{mmol} / \mathrm{L} \mathrm{Mg}^{2+}, 132 \mathrm{mmol} / \mathrm{L} \mathrm{Cl}^{-}, 3.7$ $\mathrm{mM}$ glucose, $6 \mathrm{mM}$ urea, $25 \mathrm{mmol} / \mathrm{L} \mathrm{HCO}_{3}^{-}, \mathrm{pH} 7.33 ; \mathrm{PCO}_{2}$, $6.1 \mathrm{kPa} ; \mathrm{PO}_{2} ; 5.7 \mathrm{kPa}$ ) through needles incorporated into the sides of the window. The volume of fluid directly beneath the window was $500 \mu \mathrm{L}$ and was contiguous with the periarachnoid space. 
Pial arterioles 40 to $150 \mu \mathrm{m}$ in diameter were observed with a dissecting microscope. Diameters were measured with video micrometer coupled to a television camera mounted on the microscope and a video monitor.

Measurement of Microvascular Responses. Arachidonic acid. Windows were flushed with aCSF, and control measurements of pial arteriolar diameter, arterial blood pressure, blood gases, and $\mathrm{pH}$ were taken. After $10 \mathrm{~min}$, cortical periarachnoid fluid was collected for prostanoid analysis, and arachidonic acid was then applied at $2 \mathrm{mg} / \mathrm{L}$ (in aCSF). Measurements of pial arteriolar diameter were made for $10 \mathrm{~min}$, and the aCSF was collected for prostanoid analysis. Arachidonic acid at $20 \mathrm{mg} / \mathrm{L}$ then was applied similarly.

Hypercapnia. After flushing the window with aCSF, control measurements of pial arteriolar diameter, arterial blood pressure, blood gases, and $\mathrm{pH}$ were taken. Hypercapnia was produced by ventilating with a $10 \% \mathrm{CO}_{2}, 21 \% \mathrm{O}_{2}$, and $69 \% \mathrm{~N}_{2}$ mixture. Pial arteriolar diameter and arterial pressure were measured. After 10 min of hypercapnia, cortical periarachnoid fluid was collected, and an arterial blood sample for blood gases and $\mathrm{pH}$ analysis was drawn.

Experimental Design. The experimental design consisted of initial measurements and treatments (arachidonic acid or hypercapnia), administration of indomethacin, repeated measurements and treatments over $3 \mathrm{~h}$, and then a repeat administration of indomethacin. After indomethacin trihydrate (gift from Merck Sharp and Dohme Research Laboratories, Rahway, NJ) (5 mg/ $\mathrm{kg}$, i.v.) was administered, $45 \mathrm{~min}$ were allowed to pass before examinations of responses to arachidonic acid or hypercapnia were repeated. Five $\mathrm{mg} / \mathrm{kg}$ of indomethacin were used in these experiments because previous experiments (2) showed that this dose effectively inhibits conversion of topical arachidonic acid to prostanoids on the brain surface and blocks vasodilation to hypercapnia. The 45-min period before resuming experiments was allowed, because we know from previous experiments that dilations to both exogenous arachidonic acid and hypercapnia were inhibited at about this time $(2,4,5)$. Treatments (arachidonic acid or hypercapnia) were given at 1,2 , and $3 \mathrm{~h}$ after indomethacin. Then a second administration of indomethacin was given and, $30 \mathrm{~min}$ later, a final control period and treatment with either arachidonic acid or hypercapnia was carried out.

The animal protocols were reviewed and approved by the Animal Care and Use Committee of the University of Tennessee, Memphis.

Measurement of Prostanoids. In cortical periarachnoid CSF, 6-keto-PGF ${ }_{1 \alpha}$ and $\mathrm{PGE}_{2}$ were analyzed by RIA against an aCSF matrix as described previously (13). All unknowns were processed at three dilutions, with parallelism between the unknown dilution curve and the standard curve required before the result was used. Sample dilutions allowed analysis of 6-keto-PGF i $_{\alpha}$ and $\mathrm{PGE}_{2}$ concentrations between 100 and $50000 \mathrm{ng} / \mathrm{L}$. Nondetectable levels were recorded as $50 \mathrm{ng} / \mathrm{L}$ and values greater than $50000 \mathrm{ng} / \mathrm{L}$ as $50000 \mathrm{ng} / \mathrm{L}$ for statistical purposes. Our antibodies cross-react minimally $(<1 \%)$ with $\mathrm{PGF}_{2 \alpha}$, thromboxane $\mathrm{B}_{2}$, and $\mathrm{PGD}_{2}$. Furthermore, 6-keto-PGF $\mathrm{PG}_{1<}$ and $\mathrm{PGE}_{2}$ are not displaced from their respective antibodies by arachidonic acid $(30 \mathrm{mg} / \mathrm{L})$; 5-hydroxyeicosatetraenoic acid or 15-hydroxyeicosatetraenoic acid $(1 \mathrm{mg} / \mathrm{L}) ; \mathrm{LTB}_{4}, \mathrm{LTC}_{4}, \mathrm{LTD}_{4}$, or $\mathrm{LTE}_{4}(5 \mathrm{mg} /$ $\mathrm{L})$; or lipoxin $\mathrm{A}_{4}$ or lipoxin $\mathrm{B}_{4}(10 \mu \mathrm{g} / \mathrm{L})$.

Statistical Analysis. All values are presented as means \pm SEM. Comparisons among populations used analysis of variance with repeated measures. Fisher protected least significant difference was used to determine differences between groups. $p<0.05$ was required for inference that populations were different.

\section{RESULTS}

The effects of indomethacin on pial arteriolar responses to topical arachidonic acid are shown in Table 1 and Figure 1. Before treatment with indomethacin, topical arachidonic acid

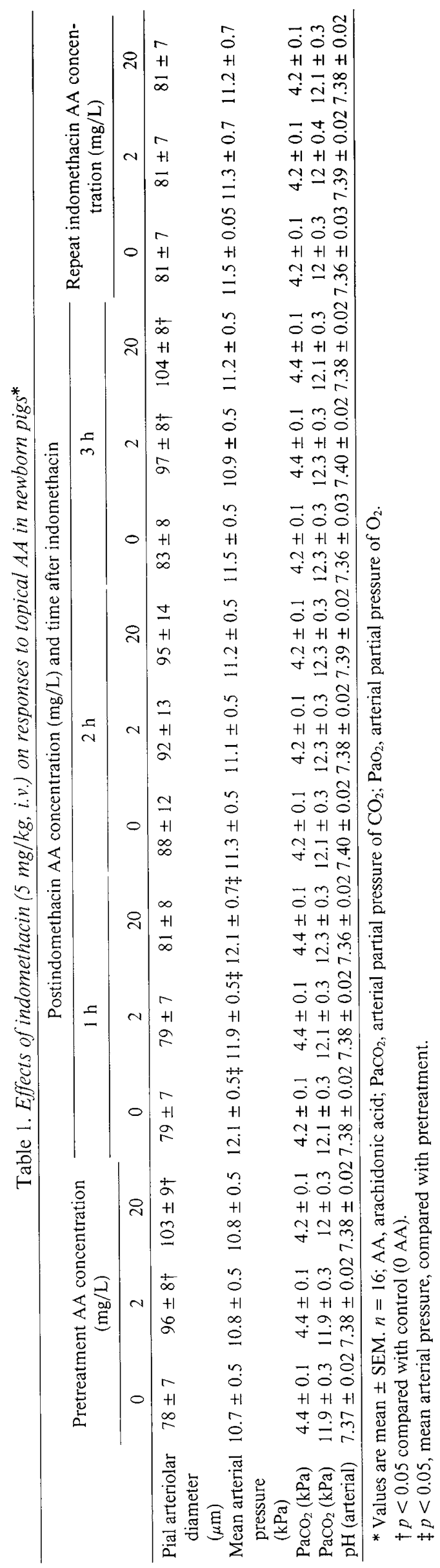




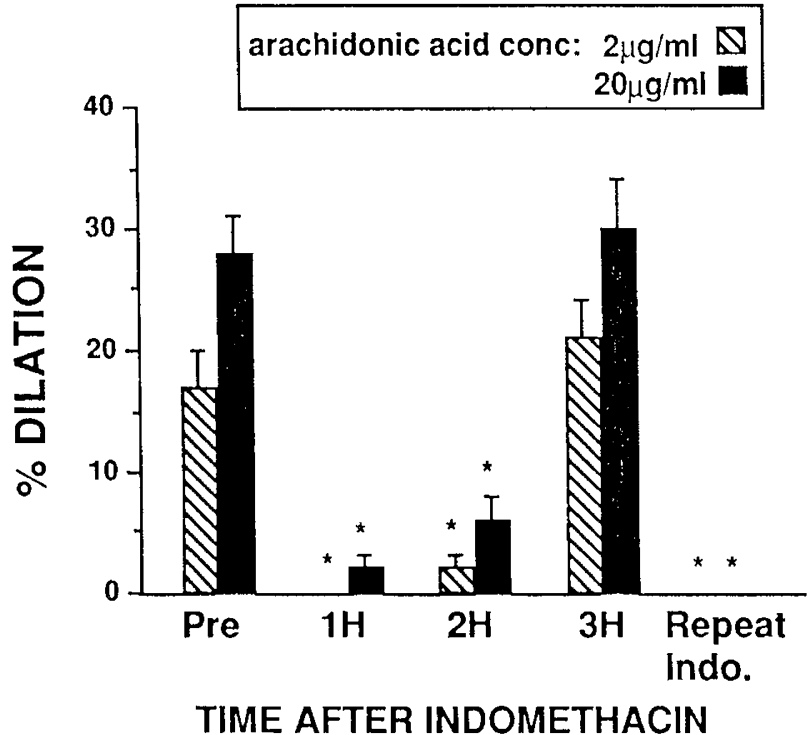

Fig. 1. Effect of indomethacin $(5 \mathrm{mg} / \mathrm{kg}$ i.v. $)$ on dilation of newborn pig pial arterioles, in vivo, to topical arachidonic acid. Values are mean \pm SEM. $\mu \mathrm{g} / \mathrm{mL}=\mathrm{mg} / \mathrm{L} . n=15$ piglets. ${ }^{*}, p<0.05$ compared with before indomethacin treatment $(\operatorname{Pre})$.

caused pial arteriolar dilation of $17 \pm 3 \%$ and $28 \pm 3 \%$ at $2 \mathrm{mg} /$ $\mathrm{L}$ and $20 \mathrm{mg} / \mathrm{L}$, respectively. Approximately $1 \mathrm{~h}$ after treatment with $5 \mathrm{mg} / \mathrm{kg}$ indomethacin i.v., arachidonic acid did not cause dilation of pial arterioles. Responses appeared to begin to return at $2 \mathrm{~h}$ after treatment and the vasodilation of pial arterioles to arachidonic acid had returned to preindomethacin levels by $3 \mathrm{~h}$ after treatment. Repeat administration of indomethacin after return of responses to topical arachidonic acid completely abolished vasodilation in response to arachidonic acid. Treatment with indomethacin decreased prostanoids in cortical CSF during control conditions. Indomethacin caused decreases in resting levels of 6-keto-PGF ${ }_{1 \alpha}$ (from $1031 \pm 119$ to $452 \pm 51 \mathrm{ng} / \mathrm{L}$ ) and $\mathrm{PGE}_{2}$ (from $2556 \pm 488$ to $566 \pm 133 \mathrm{ng} / \mathrm{L}$ ) by $1 \mathrm{~h}$ posttreatment. The residual high levels are probably the result of previous synthesis, because we have found before that, if the cranial window is flushed with aCSF repeatedly after indomethacin treatment, prostanoid concentrations in cortical periarachnoid CSF will be at nondetectable levels by $45 \mathrm{~min}(2,4)$. The reductions in resting levels of CSF 6-keto-PGF $\mathrm{PG}_{1 \alpha}$ and $\mathrm{PGE}_{2}$ were sustained at 2 and $3 \mathrm{~h}$ posttreatment $(256 \pm 102$ and $128 \pm 40$ $\mathrm{ng} / \mathrm{L}$ for 6-keto-PGF $\mathrm{PG}_{1 \alpha}$ and $472 \pm 99$ and $629 \pm 186$ for $\mathrm{PGE}_{2}$, $\mathrm{ng} / \mathrm{L}$, respectively). However, inhibition of conversion of exogenous arachidonic acid to prostanoids was not sustained for the 3-h period. Instead, the time course of inhibition of conversion of arachidonic acid to prostanoids as monitored by 6 -keto-PGE a $_{1}$ and $\mathrm{PGE}_{2}$ concentrations in CSF under the cranial windows was similar to the time course of inhibition of vasodilation to arachidonic acid by indomethacin (Figs. 2 and 3). Thus, $1 \mathrm{~h}$ after indomethacin treatment, conversion of exogenous arachidonic acid to 6-keto-PGF ${ }_{1 \alpha}$ and $\mathrm{PGE}_{2}$ was minimal. By $2 \mathrm{~h}$, small but significant conversion occurred, and by $3 \mathrm{~h}$, the fractional increases in prostanoids after application of arachidonic acid were the same as before indomethacin treatment. The absolute levels of prostanoids achieved, on the other hand, remained reduced even $3 \mathrm{~h}$ after indomethacin compared with before indomethacin $(20 \mathrm{mg} / \mathrm{L}$ arachidonic acid; $34 \pm 6$ to $8 \pm 3 \mu \mathrm{g} / \mathrm{L}$ and $4.5 \pm 0.5$ to $0.7 \pm 0.2 \mu \mathrm{g} / \mathrm{L}$ for $\mathrm{PGE}_{2}$ and 6 -keto-PGF $\mathrm{PG}_{1 \alpha}$, respectively). Retreatment with indomethacin again abolished prostanoid production from exogenous arachidonic acid.

The effects of indomethacin on the responses of newborn pig pial arterioles to hypercapnia are shown in Table 2 and Figure 4. The level of hypercapnia used in these experiments was an arterial partial pressure of $\mathrm{CO}_{2}$ of approximately $8.7 \mathrm{kPa}(65 \mathrm{~mm}$

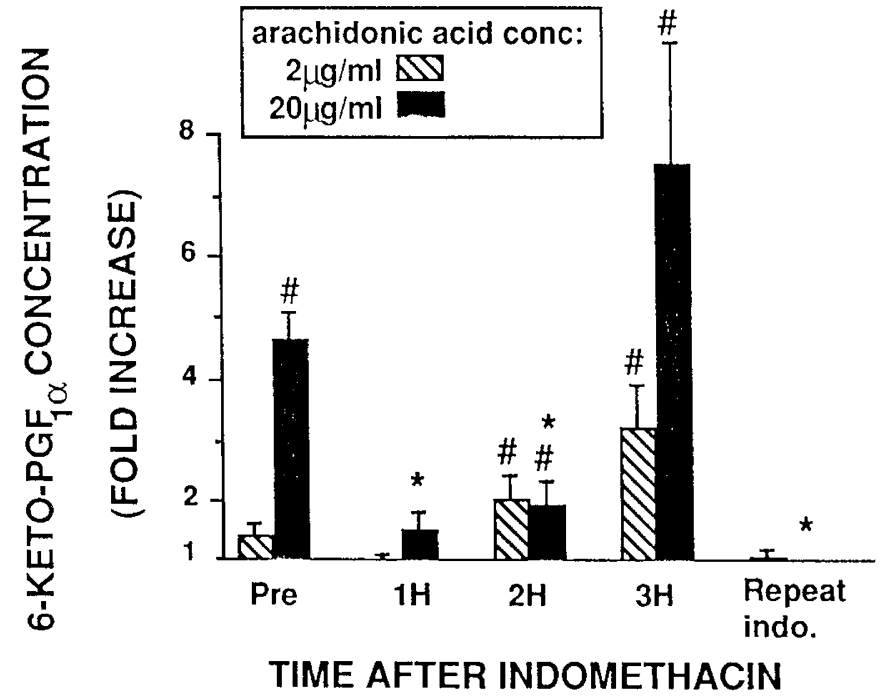

Fig. 2. Effect of indomethacin $(5 \mathrm{mg} / \mathrm{kg}$ i.v.) on conversion of topically applied arachidonic acid to 6-keto-PGF ${ }_{1 \alpha}$ on the newborn pig brain surface. Data are presented as fold increase in 6-keto-PGF ${ }_{1 \alpha}$ in CSF after arachidonic acid treatment. Values are mean \pm SEM. $\mu \mathrm{g} / \mathrm{mL}=\mathrm{mg} / \mathrm{L} . n$ $=9$ piglets. ${ }^{*}, p<0.05$ compared with before indomethacin treatment (Pre). \#, $p<0.05$ compared with no change.

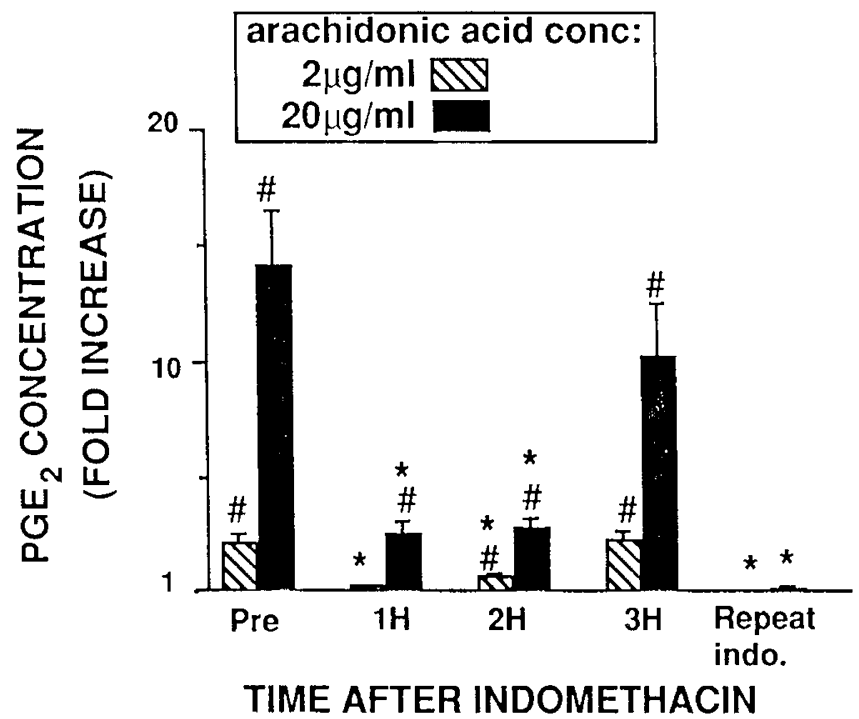

Fig. 3. Effect of indomethacin $(5 \mathrm{mg} / \mathrm{kg}$ i.v.) on conversion of topically applied arachidonic acid to $\mathrm{PGE}_{2}$ on the newborn pig brain surface. Data are presented as fold increases in $\mathrm{PGE}_{2}$ in $\mathrm{CSF}$ after arachidonic acid treatment. Values are mean \pm SEM. $\mu \mathrm{g} / \mathrm{mL}=\mathrm{mg} / \mathrm{L} . n=9$ piglets. ${ }^{*}, p<0.05$ compared with before indomethacin treatment (Pre). \#, $p<$ 0.05 compared with no change.

$\mathrm{Hg}$ ) (Table 2). Before indomethacin treatment, this level of hypercapnia produced dilation of pial arterioles of $54 \pm 4 \%$. Indomethacin treatment totally abolished the vasodilation in response to hypercapnia administered approximately $1 \mathrm{~h}$ after indomethacin treatment. By $2 \mathrm{~h}$ after treatment, significant vasodilation was produced by hypercapnia $(27 \pm 4 \%)$ that remained reduced compared with pretreatment dilation. Three $h$ after indomethacin treatment, vasodilation of pial arterioles in response to hypercapnia $(52 \pm 4 \%)$ was identical to that seen before indomethacin treatment. This vasodilation was again totally abolished by repeat treatment with indomethacin. Although hypercapnic vasodilation had returned by $3 \mathrm{~h}$ after indomethacin, we were unable to detect significant return of cerebral prostanoid synthesis in response to hypercapnia at this time, as monitored by cortical periarachnoid CSF prostanoids. Thus, 


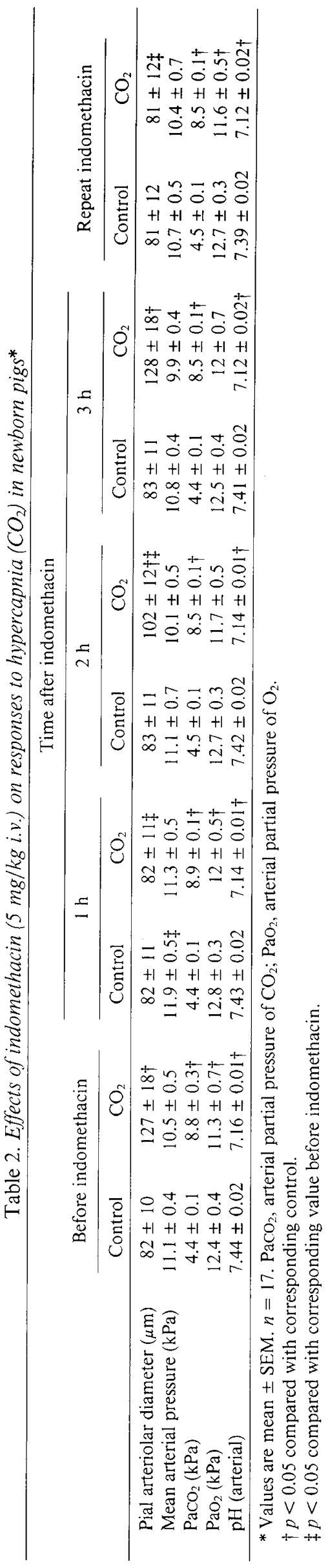

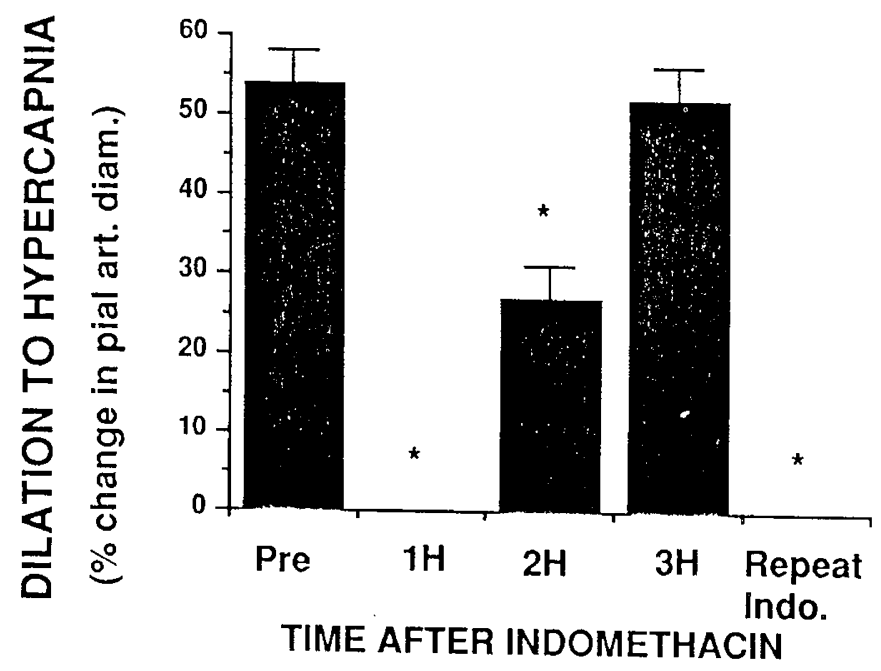

Fig. 4. Effect of indomethacin $(5 \mathrm{mg} / \mathrm{kg}$ i.v.) on dilation of newborn pig pial arterioles to hypercapnia. Repeat indicates $30 \mathrm{~min}$ after another administration of indomethacin $(5 \mathrm{mg} / \mathrm{kg}$ i.v. $)$. Values are mean $\pm \mathrm{SEM}$. $n=17$ piglets. ${ }^{*}, p<0.05$ compared with before indomethacin treatment (Pre).

returning prostanoid synthesis in response to hypercapnia could only be detected in about one third of the piglets examined at 3 $\mathrm{h}$ after indomethacin treatment.

\section{DISCUSSION}

The present study found that in newborn pigs i.v. administration of indomethacin inhibits dilation of pial arterioles to topical application of arachidonic acid and to hypercapnia, as reported previously. The inhibitions by indomethacin of vasodilations to both topical arachidonic acid and hypercapnia are lost by $3 \mathrm{~h}$ posttreatment, at which time vasodilations to both these stimuli are similar to those before indomethacin treatment. Repeat treatment with indomethacin after return of responses blocks the vasodilation to both stimuli again. The possibility of short duration of cerebral vascular effectiveness of indomethacin when administered systemically, as reported here, needs to be considered both when it is used as a probe for understanding contributions of PGH synthase products to control of cerebral circulation and when it is used therapeutically in attempts to alter the newborn cerebral circulation.

Demonstration of the functional significance of a relationship between a purported mediator and a response must include either inhibition of the synthesis of the mediator, scavenging of the mediator, or receptor blockade. Many hypothesized physiologic roles for prostanoids in control of cerebral circulation involve dilator effects, but effective receptor blockers for dilator prostanoids do not exist, and effective removal is not possible. Therefore, much information related to the functional significance of prostanoids is from experiments using inhibitors of PGH synthase. The most frequently used inhibitor is indomethacin, a compound that can effectively inhibit cerebral synthesis of prostanoids when adequate doses are used (2). In adult humans, indomethacin given intramuscularly rapidly (within $30 \mathrm{~min}$ ) enters the CSF, demonstrating the ability to cross the bloodbrain barrier (1). The ability of indomethacin to cross the bloodbrain barrier may be greater than other nonsteroidal antiinflammatory drugs because, although also strongly protein bound, the free indomethacin in plasma is greater than the free levels of others with the exception of salicylates (8). In newborn pigs (4, $5)$, and apparently newborn humans $(10-12)$, hypercapnic cerebral vasodilation is reduced or abolished by indomethacin. This finding, coupled with measurements of cerebral synthesis of prostanoids induced by hypercapnia $(4,13)$ and the inability of radical scavengers to alter the responses (14), suggests that pros- 
tanoids play a role in hypercapnic cerebral vasodilation in newborn pigs and human infants. Similarly, studies in adult primates, rats, and gerbils found inhibition of hypercapnic vasodilation after indomethacin (15-17). On the other hand, some investigators using rabbits, dogs, and cats were unable to detect an effect of indomethacin on hypercapnic cerebral vasodilation (18-22), whereas others reported inhibition of hypercapnic cerebral vasodilation after indomethacin in these same three species (23-27).

A report on piglets that examined changes in blood flow to the brain in response to hypercapnia indicated that vasodilatory responses to hypercapnia that are abolished by indomethacin return within $2 \mathrm{~h}$ after indomethacin treatment $(9)$. Such findings suggest PGH synthase inhibition by indomethacin wears off quickly, or another effect of indomethacin unrelated to $\mathrm{PGH}$ synthase inhibition contributed to the decreased vasodilation in response to hypercapnia. The present study compared the return of responses to hypercapnia with the return of responses to the prostanoid precursor, arachidonic acid, as an index of activity of PGH synthase. We found that both began to return at $2 \mathrm{~h}$, although only the response to hypercapnia was significant. By 3 $\mathrm{h}$ after indomethacin treatment, responses to both hypercapnia and exogenous arachidonic acid had returned completely to the preindomethacin levels. Furthermore, retreatment with indomethacin again totally abolished vasodilation to both stimuli, suggesting return of responses was due not to alternative mechanisms of vasodilation that were not affected by indomethacin but to insufficient residual indomethacin.

Although indomethacin did not inhibit fractional increases in prostanoids caused by arachidonic acid treatment at $3 \mathrm{~h}$ posttreatment, the decreases in baseline prostanoid concentrations were sustained and the absolute levels of 6-keto-PGF ${ }_{1 \kappa}$ and $\mathrm{PGE}_{2}$ achieved upon treatment with arachidonic acid were less $3 \mathrm{~h}$ after indomethacin treatment than before. Such a finding coupled with complete return of vasodilation in response to arachidonic acid by $3 \mathrm{~h}$ could suggest that recovery of prostanoid synthetic capacity by vascular cells returns more quickly after indomethacin treatment than does this capacity by the rest of the brain. Such selective return would allow return of prostanoid synthesis and dilator responses by the vasculature, whereas cortical CSF prostanoids were reduced because the contribution by other cell types (neurons and/or glia) remained inhibited. Although such a selective return of synthesis in the vasculature would explain the present data, no other data to support this hypothesis are available. Further complicating the interpretations of these data is the inability to detect return of significant increases in cortical periarachnoid prostanoids in response to hypercapnia $3 \mathrm{~h}$ after indomethacin treatment. Dilation to arachidonic acid, along with significant conversion of arachidonic acid to prostanoids $3 \mathrm{~h}$ after indomethacin treatment, indicates that some PGH synthase activity has returned. Therefore, because the hypercapnic vasodilation returned coincidently with the ability of arachidonic acid to produce dilation and to be converted to prostanoids, it seems reasonable to propose that this returning PGH synthase activity is sufficient to facilitate vasodilation to hypercapnia, even though detectable increases in the CSF over the brain surface did not occur. Such findings clearly demonstrate that cerebral prostanoids do not act as hormones that accumulate in cortical CSF whereby dilation is produced. The mechanism by which prostanoids appear to facilitate hypercapnia-induced cerebral vasodilation remains unclear, but the present data may imply that only localized, limited synthesis is necessary. It remains possible that, in addition to inhibiting PGH synthase, another effect of indomethacin could contribute to the ability of this compound to block dilation to exogenous arachidonic acid and hypercapnia. Indomethacin has been reported to inhibit cyclic AMP-dependent protein kinase (28). Because cAMP-dependent protein kinase probably is involved in prostanoid-induced vasodilation, such inhibition could amplify the ability of indomethacin to eliminate responses.

The high degree of effectiveness of indomethacin at $5 \mathrm{mg} / \mathrm{kg}$ to block PGH synthase that we report seems to contrast with the very weak effect reported by Chemtob et al. (29). In their piglets, indomethacin $(3 \mathrm{mg} / \mathrm{kg})$ had only slight effects on arterial and sagittal sinus prostanoids, suggesting the effect would have been even less on conversion of arachidonic acid to prostanoids on the brain surface. The difference is unlikely to be the result of the lower dose $(3 \mathrm{mg} / \mathrm{kg}$ ) used because we found previously that $2 \mathrm{mg} / \mathrm{kg}$ decreased cortical periarachnoid prostanoids markedly and inhibited conversion of topically applied arachidonate to prostanoids (2). It is also unlikely that indomethacin is affecting cortical periarachnoid prostanoids more than plasma prostanoids, because we found indomethacin at $5 \mathrm{mg} / \mathrm{kg}$ decreased plasma 6-keto-PGF la $_{10}$ to nondetectable levels by $30 \mathrm{~min}$ after administration (4) and blocked the increase in net cerebral 6 keto-PGF ${ }_{1 \ll}$ production (sagittal sinus minus arterial times flow) caused by hypotension (30). We do not know the reason the measured plasma prostanoid levels did not decline more with indomethacin treatment of $3 \mathrm{mg} / \mathrm{kg}$ in the report of Chemtob et al. At $10 \mathrm{mg} / \mathrm{kg}$, they also found plasma levels of prostnoids to be reduced to very low or nondetectable concentrations.

Whether the duration of effectiveness of indomethacin on the cerebral circulation of the newborn human infant is equally short as that on the piglet is not known. However, inasmuch as very low doses of indomethacin are used in treating newborn infants, the likelihood that the effects on the cerebral circulation are much shorter than previously assumed is great. Indomethacin has been reported to have beneficial prophylactic effects in prevention and/or reduction of severity of intraventricular/periventricular hemorrhage in premature babies (31-33). One proposed mechanism for such effects is reducing the fluctuation in cerebral blood flow in response to changes in carbon dioxide and blood pressure changes. The possibility that any such effects could be lost within hours after administration must now be considered.

Acknowledgments. The authors thank A. Fedinec, N. Leffler, and M. Jackson for technical assistance.

\section{REFERENCES}

1. Bannwarth B. Netter P. Lapicque F. Pere P. Thomas P. Gaucher A 1990 Plasma and cerebrospinal fluid concentrations of indomethacin in humans. Eur J Clin Pharmacol 38:343-346

2. Leffler CW. Busija DW 1985 Arachidonate metabolism on the cerebral surface of newborn pigs. Prostaglandins 30:811-818

3. Leffler CW. Busija DW. Fletcher AM. Beasley DG, Hessler JR. Green RS 1985 Effects of indomethacin upon cerebral hemodynamics of newborn pigs. Pediatr Res 19:1160-1164

4. Leffler CW Busija DW 1985 Prostanoids in cortical subarachnoid cerebrosinal fluid and pial arterial diameter in newborn pigs. Circ Res 57:689-694

5. Wagerle LC, Mishra OP 1988 Mechanisms of $\mathrm{CO}_{2}$ responses in cerebral arteries of the newborn pig: role of phospholipase. cyclooxygenase, and lipoxygenase pathways. Circ Res 62:1019-1026

6. Leffler CW, Busija DW 1987 Prostanoids and pial arteriolar diameter in hypotensive newborn pigs. Am J Physiol 252:H687-H691

7. Shohami E. Sidi A 1984 Accumulation of prostacyclin in rat brain during hemorrhagic hypotension: possible role of $\mathrm{PGI}_{2}$ in autoregulation. $\mathrm{J}$ Cereb Blood Flow Metab 4:107-109

8. Day RO. Graham GG. Williams KM. Champion GD. de Jager J 1987 Clinical pharmacology of non-steroidal anti-inflammatory drugs. Pharmacol The 33:383-433

9. Lozon M. Rudensky B, Randle C. Hipps R, Meadow W 1991 Effects of indomethacin on cerebral $\mathrm{O}_{2}$ regulation and cerebrovascular reactivity: in situ measurements in neonatal piglets. Pediatr Res 29:223A(abstr)

10. Cowan F 1986 Indomethacin, patent ductus arteriosus, and cerebral blood flow. J Pediatr 109:314-344

11. Laudignon N. Chemtob S. Bard H. Aranda JV 1988 Effect of indomethacin on cerebral blood flow velocity of premature newborns. Biol Neonate $54: 254-262$

12. Edwards AD, Wyatt JS, Richardson CE, Potter A, Cope M, Delpy DT Reynolds EOR 1990 Effects of indomethacin on cerebral hemodynamics in very preterm infants. Lancet 335:1491-1495

13. Wagerle LC, DeGuilio PA, Mishra OP, Delivoria-Papadopoulos M 1991 Effect of dexamethasone on cerebral prostanoid formation and pial arteriola reactivity to $\mathrm{CO}_{2}$ in newborn pigs. Am J Physiol 260:H1313-H1318

14. Leffler CW, Mirro R, Thompson C, Shibata M, Armstead WM, Pourcyrous $\mathrm{M}$, Thelin O 1991 Activated oxygen species do not mediate hypercapnia- 
induced cerebral vasodilation in newborn pigs. Am J Physiol 261:H335$\mathrm{H} 342$

15. Crockard HA, Iannotti F. Lads G 1982 Cerebrovascular effects of prostaglandin inhibitors in the gerbil. J Cereb Blood Flow Metab 2:67-72

16. Pickard JD. Mackenzie ET 1973 Inhibition of prostaglandin synthesis and the response of the baboon cerebral circulation to carbon dioxide. Nature New Biol 245:187-188

17. Sakabe T. Siesjö BK 1979 The effect of indomethacin on the blood flow metabolism couple in the brain under normal. hypercapnic and hyptoxic conditions. Acta Physiol Scand 107:283-284

18. Busija DW 1983 Role of prostanoids in the response of the cerebral circulation to carbon dioxide in awake rabbits. J Cereb Blood Flow Metab 3:376-378

19. Wei EP. Ellis EF. Kontos HA 1980 Role of prostaglandins in pial arteriolar resonses to $\mathrm{CO}_{2}$ and hypoxia. Am J Physiol 238:H226-H230

20. Busija DW. Heistad DD 1983 Effects of indomethacin on cerebral blood flow during hypercapnia in cats. Am J Physiol 244:H519-H524

21. Jackson EK, Gerkins JF. Zimmerman JB. Lederman HD. Oates JA, Workman RJ. Branch RA 1983 Prostaglandin biosynthesis does not participate in hypercapnia-induced cerebral vasodilation in the dog. J Pharmacol Exp Ther 226:486-492

22. Cuypers J. Cuevas A. Duisberg R 1978 Effect of indomethacin on $\mathrm{CO}_{2}$-induced hyperemia $\left(\mathrm{CO}_{2}\right.$-response) in the rabbit brain. Neurochirurgia 21:62-66

23. Ruszczewsi P. Herbacynska-Cedro K 1978 Release of prostaglandin-like substance into cerebral venous blood in conditions injurious to brain in the dog. Acta Physiol Pol 29:498-499

24. Vlahov V 1976 The role of prostaglandins in the regulation of cerebral vessel wall reactivity. In: Cervos-Navarro J, Betz E. Matakas F. Wullenweber R (eds) The Cerebral Vessel Wall. Raven Press. New York, pp 143-147
25. Shigeno S, Fritschka E, Shigeno T, Brock M 1983 Effect of indomethacin on CBF during and after focal cerebral ischemia in the cat. J Cereb Blood Flow Metab 3(suppl 1):S309-S310

26. Bill A 1979 Effects of indomethacin on regional blood flow in conscious rabbits: a microsphere study. Acta Physiol Scand 105:437-442

27. Pinard E, Rougier P, Seylaz J 1983 Effects of inhibition of prostaglandin synthesis on cerebral blood flow and its regulation. J Cereb Blood Flow Metab 3(suppl 1):S305-S306

28. Kantor HS, Hampton M 1978 Indomethacin in submicromolar concentrations inhibits cyclic AMP-dependent protein kinase. Nature 276:841-842

29. Chemtob S, Beharry K, Barna T, Varma DR, Aranda JV 1991 Differences in the effects in the newborn piglet of various nonsteroidal antiinflammatory drugs on cerebral blood flow but not on cerebrovascular prostaglandins. Pediatr Res 30:106-111

30. Leffler CW, Busija DW, Beasley DG, Fletcher AM 1986 Maintenance of cerebral circulation during hemorrhagic hypotension in newborn pigs: role of prostanoids. Circ Res 59:562-567

31. Ment LR, Duncan CC, Ehrenkranz RA, Kleinman CS, Pitt BR, Taylor KJW, Scott DT. Stewart WB, Gettner P 1985 Randomized indomethacin trial for prevention of intraventricular hemorrhage in very low birth weight infants.
$\mathrm{J}$ Pediatr 107:937-943

32. Hanigan WC, Kennedy G, Roemisch F, Anderson R, Cusack T, Powers W 1988 Administration of indomethacin for prevention of periventricularintraventricular hemorrhage in high-risk neonates. J Pediatr 112:941-947

33. Bada HS, Green RS, Pourcyrous M, Leffler CW, Korones SB, Magill HL. Arheart K, Fitch CW, Anderson GD. Somes G, Tullis K. Campbell J 1989 Indomethacin reduces the risks of severe intraventricular hemorrhage. J Pediatr 115:631-637 